\title{
Some Data on Surgical Treatment of Gastroesophageal Reflux
}

\author{
Saimir Heta, Hysen Heta \\ University Hospital Center, Pediatric Surgery, Pediatrician Surgeon, Tirana, Albania
}

Email address:

sa.heta@yahoo.com (S. Heta)

\section{To cite this article:}

Saimir Heta, Hysen Heta. Some Data on Surgical Treatment of Gastroesophageal Reflux. American Journal of Pediatrics. Vol. 3, No. 5, 2017, pp. 58-61. doi: 10.11648/j.ajp.20170305.16

Received: December 28, 2016; Accepted: February 6, 2017; Published: October 24, 2017

\begin{abstract}
Gastroesophageal refluxis such a terminal illness it's solution is surgical intervention that has been a challenge for therapeutic treatment. This type of treatment has started properly by positioning the child during breastfed, by the use of drugs, such as omeprazole. Purpose of the study: determining the efficiency of surgical techniques for gastroesophageal reflux, comparison of two methods: open and laparoscopic, determination of the advantages and disadvantages of techniques. The study was conducted over a 4 year period, from 1 october 2011 to 20 february 2015 . The study involved 59 children, operated for gastroesophageal reflux with laparoscopic method and for the same period, 14 children operated by the open method. The duration of the operation $(48 \mathrm{~min}$ ) is greater in the group treated with laparoscopy, compared with open method (14min). In the open method we had 2 cases of wound inflamation. In both groups, a significant statistical difference is seen at the use of antibiotics. The duration of stay of patients with laparoscopic method (2 days), is significantly lower. In conclusion, it is seen that sparing incision, infant morbidity of fundoplication by Nissen, performed with laparoscopy, has the same success as it was conducted by the open method. Regime and placement of food is in both cases, at the same efficiency, in both operated groups.
\end{abstract}

Keywords: Gastrointestinal Reflux, Laparoscopy, Open Method, Nissen Fundoplication

\section{Introduction}

The therapeutic treatment of gastroesophageal reflux implies a series of measures which conclude at the end, at surgical treatment. It should be noted that surgical treatment should be the ultimate weapon to be used for the treatment of this pathology, because of complications and recurrence itself that may give this surgery. The vomiting without strain that happens after food, at breastfed children,is a symptom that can't be called a disease, if breastfed children fade away after a meal, and we keep at elevated position.

With the maturation of the lower esophageal sphincter, it goes away with time and disappears almost entirely. Seeing that symptom subsided from elevated position, it was thought to be used at chair of chalasise. Pretty soon it was noted that this led to the addition of reflux [1].

Use of ousted position is not without consequences and must be applied with care, according to a study [2], noted that the use of this position must be accepted as a treatment for the side effects of drug-related therapy. In a study [3] which sees the connection of SIDS position (Sudden Infant
Death Syndrome),it is recommendedthe use of lateral positioners and that the child should be placed in a position in the back. This is also the recommendation of the AAPS (American Academy of Pediatric Surgery).

Another method of treatment for these children is obesity and consistency of food they receive, use of motilium or cisapridprocinetic, which are agents that have very good clinical effects. Preparation is the first that provides augmentation of peristalsis, increased pressure to lower esophageal sphincter and gastric emptying rush [4]. But the discovery of cardiac problems that can give this product, made that in America to be removed from the market [5]. However, it is being used here, but keep in mind that the treatment should be as limited and cautious because of these complications.

The use of $\mathrm{H}_{2}$ receptor antagonists (ranitidine) was not very practical for young children. Omeprazole or better proton pump inhibitors, for a long time already are part of therapy. Although, early reports were very good and 
enthusiastic about this new drug in its use to children should not overestimate or underestimate. This is a drug which has its own side effects as reported [6, 7] which can give gastrointestinal infections, bone fractures, hypomagnesaemia or excessive, and an increase in acidity (rebound) after treatment ends. Many scholars in the years before the release date of this drug rejected surgical treatment of reflux itself, saying that treatment with this preparation would be the final solution to the problem of reflux. Omeprazole should be used as the curing medicine in cases where surgery fails it on grounds that it is good therapy, but often not healing.

\section{Materials and Methods}

Principles of surgical treatment of gastroesophageal reflux are based on the anatomy and physiology of the lower esophageal sphincter. They include the extent of intraabdominal esophagus, emphasizing the angle of His, increased pressure in esophago-gastric junction, closing the crura.

Purpose of the study:

1. Determining the efficiency of surgical techniques for gastroesophageal reflux.

2. Comparison of two methods: open and laparoscopic.

3. Determination of the advantages and disadvantages of techniques operators.

The study was conducted over a 4 year period, from 1 october2011 to 20 february 2015. The study involved 59 children operated for gastroesophageal reflux with laparoscopic method and for the same period 14 children operated by the open method.

By sex in these two groups, we had 34 boys and 25 girls in the first group of laparoscopic method and 8 boys and 6 girls in the group with open method. The average age of the children that were treated: for boysis 12 years and for girlsis 13 years in the group of laparoscopic method; boys and girlsare aged 7 years and 8 years in the group of open method.

Data were collected prospectively on the basis of this file type. The data are collected and described in such a way that they simply be analyzed statistically.

\section{Results}

All the results are represented at specific tables. At table 1 we can see the results according the duration of surgery, like a procedure at cases of laparoscopy and at cases of open method.

Table 1. Duration of surgery:laparoscopy method vsopen method.

\begin{tabular}{lllllll}
\hline $\begin{array}{l}\text { Duration of } \\
\text { operation/min }\end{array}$ & N & AV & SD & $\min$ & $\max$ & $\mathbf{P}$ \\
\hline Laparoscopy & 59 & 162 & 69 & 60 & 385 & 0.0005 \\
Open Process & 14 & 93 & 24 & 75 & 125 & 0 \\
\hline
\end{tabular}

The duration of the operation is greater in the group treated with laparoscopy, compared with the open method. This difference is statistically significant.
Table 2. Duration of operation:laparoscopy (homogenization) vs open method.

\begin{tabular}{llllll}
\hline $\begin{array}{l}\text { Duration of } \\
\text { operationMin }\end{array}$ & N & AV & SD & Min & Max \\
\hline $\begin{array}{l}\text { Laparoscopy } \\
\text { homogenized }\end{array}$ & 48 & 95.34 & 27.9 & 60 & 118 \\
Open Process & 14 & 93 & 24.4 & 75 & 125 \\
\hline
\end{tabular}

$P$ value is 0.0975

There we found statistically significant differences in the duration of the operation between the two methods.

Table 3. Wound Infection.

\begin{tabular}{llllll}
\hline \multirow{2}{*}{ Infection } & \multicolumn{2}{l}{ Frequency } & \multicolumn{2}{l}{ Percentage } & P \\
\cline { 2 - 5 } & Yes & No & Yes & No & \\
\cline { 1 - 4 } $\begin{array}{l}\text { Laparoscopic } \\
\text { method }\end{array}$ & 1 & 58 & 1.69 & 98.31 & 0.0922 \\
\begin{tabular}{l} 
Open method \\
\hline
\end{tabular} & 2 & 12 & 14.29 & 85.71 & \\
\hline
\end{tabular}

In the open method we had 2 cases of wound redness.

Table 4. Pulmonary Complications.

\begin{tabular}{|c|c|c|c|c|c|}
\hline \multirow{2}{*}{$\begin{array}{l}\text { Pulmonary } \\
\text { complications }\end{array}$} & \multicolumn{2}{|c|}{ Frequency } & \multicolumn{2}{|c|}{ Percentage } & \multirow[t]{2}{*}{ Fisher's test $\mathrm{P}$} \\
\hline & Yes & No & Yes & No & \\
\hline $\begin{array}{l}\text { Laparoscopic } \\
\text { method }\end{array}$ & 52 & 7 & 88.14 & 11.86 & 0.0455 \\
\hline Open method & 9 & 5 & 64.29 & 35.71 & \\
\hline
\end{tabular}

In this series we have only one major complication of patients with pulmonary.

Observed differencesare statistically significant between the two groups.

Table 5. The antibiotic therapy at laparoscopic method.

\begin{tabular}{lll}
\hline Antibiotics & Frequency & Percentage \\
\hline Without antibiotics & 16 & 27.12 \\
With an antibiotic & 30 & 50.85 \\
With two antibiotics & 11 & 18.64 \\
With three antibiotics & 2 & 3.39 \\
Total & 59 & 100.00 \\
\hline
\end{tabular}

Antibiotics have been used as prophylaxis in 50\% of patients. In many patients antibiotics are not used either as prophylaxis.

Table 6. The antibiotic therapy at open therapy.

\begin{tabular}{lll}
\hline Antibiotics & Frequency & Percentage \\
\hline With an antibiotic & 10 & 71.43 \\
With two antibiotics & 3 & 21.43 \\
With three antibiotics & 1 & 7.14 \\
Total & 14 & 100.00 \\
\hline
\end{tabular}

In another series of patients we have used antibiotics to all patients. It is worth noting that in most cases are used as prophylaxis. 
Table 7. The statistical analysis for the use of antibiotics.

\begin{tabular}{llll}
\hline Antibiotics & $\begin{array}{l}\text { Group open } \\
\text { method }\end{array}$ & $\begin{array}{l}\text { Group } \\
\text { laparoscopy }\end{array}$ & P \\
\hline With antibiotic & 14 & 43 & \\
Without antibiotics & 0 & 16 & 0.0304 \\
Total & 14 & 59 & \\
\hline
\end{tabular}

As we see the use of antibiotics in both groups, have a significant statistical difference.

Table 8. Duration of post-operative stay (in days), laparoscopyvs open method.

\begin{tabular}{llllll}
\hline $\begin{array}{l}\text { Post-operative duration of } \\
\text { stay (days) }\end{array}$ & $\mathbf{N}$ & AV & SD & Min & Max \\
\hline Laparoscopy & 59 & 1.85 & 1.60 & 0 & 8 \\
Open Process & 14 & 5.3 & 2.23 & 4 & 9 \\
\hline
\end{tabular}

$P$ value is 0.0001

It is observed statistically significant difference between the post-operative duration of stay for patients of laparoscopy, compared with patients of open method.

Table 9. The start of food comparing at the two groups.

\begin{tabular}{lllll}
\hline \multirow{2}{*}{ Start of the food } & \multicolumn{2}{l}{ Frequency } & \multicolumn{3}{l}{ Percentage } \\
\cline { 2 - 5 } & First day & Second day & First day & Second day \\
\hline Laparoscopy & 44 & 15 & 74.57 & 25.43 \\
Open surgery & 2 & 12 & 14.29 & 85.71 \\
\hline
\end{tabular}

According Fisher's test, $\mathrm{p}$ value is $<0.0001$. Most children are fed at laparoscopic group, from the first day, where you can see a big contract with another team. The observed changing is statistically significant with $\mathrm{P}$ value $<0.0001$.

\section{Discussion}

At the age of child with gastroesophageal reflux,has long been given special attention by pediatricians, as well as by pediatrician surgeons. A pathology that in its benign characteristic is reflux, not morbid, picked up at a very large percentage of children in the first year of life, where some studies appear in $50 \%$ of cases with a maximum increase in the prevalence of $4^{\text {th }}$ month of life. Laparoscopic fundoplication is the gold standard for surgical treatment of severe GERD (Gastroesophageal Reflux Disease) and results in approximately 95\% patient satisfaction [8]. Laparoscopic Nissen and Dor fundoplication are better than Toupet fundoplication in reducing the number of reflux episodes, suppressing long reflux, increasing lower esophageal sphincter pressure (mean resting respiration) and decreasing the incidence of postoperative dysphagia [9].

The use of antibiotics is a given in both groups, analyzed and presented in tables 5,6. We analyzed the use of antibiotics that are classified into cases where we used antibiotic, classified with a double and three antibiotics used. It is clear that we have a very big difference. At the two groups clearly show that in $27 \%$ of cases in the first group,we have not used antibiotics; in the second group we have no case that we do not use antibiotics. In general, the use of antibiotic prophylaxis is used; in the second group it is used only one antibiotic in $71.42 \%$ of cases, two antibiotics in $21.43 \%$ and three antibiotics at $7.14 \%$. If we compare the open method with laparoscopy, we used two antibiotics at $18.64 \%$ and at $21.43 \%$ of cases at the group of laparoscopy; cases with three antibiotics we had respectively 2 and 1 case. The use of antibiotics in the two groups is statistically analyzed at table 7 . Here we have grouped the patients who have not used antibiotics and in patients who have used antibiotics with statistically significant difference p 0.0304 . We should note that the use of antibiotics in the second group is more liberal or after many criteria due to the bad conditions, but also because having a wound operators rather larger and more exposed, that we are forced at the use of antibiotic-prophylaxis with broader indications.

Laparoscopic antireflux surgery significantly increased baseline impedance likely reflecting recovery of mucosal integrity [10]. Duration of stay is an important clue in our discussion that we touched a little on discussingat the above problem of laparoscopic cost operators. We analyzed the data of total duration of stay of the total of patients. Duration of stay of patients in the first group was 11.85 days on average, while in the second group it was 7.25 days. In the given idea if these patients stay longer in hospital, they have a long postoperative period. But if we look at table 8 , where we have the picture of post-operative duration of stay varies, we see that the duration of stay, at the first group the average was 1.85 days, and for the second group the average of stay was 5 days. In the statistical analysis we have statistically significant difference of $p<0.0001$. This is a very important given, the often noted in the literature and in the advantages of laparoscopy. But if we look carefully at table 8 , we see the children that have emerged at the first post-operative day in the laparoscopic group. This is impossible in children operated by the open method, where the minimum duration of stay was 4 days. This data supports much data found from literature, as we have pointed out above, for not falling into repetition.

In table 9 is the statistical analysis which shows that we have a statistically significant difference of $p$ value $<0.0001$. This has a direct impact on the duration of stay and postoperative, but the impact and cost for feeding because the baby has not needed to perfusion, so practically it is reduces the cost impacts for the patient. Diet earlier in these patients, is due to children that develop virtually no post-operative ileus. The cause is minimal manipulation of the viscera, with laparoscopic method, that brings a lesser trauma and turn the temperature of the viscera preserved quite well during laparoscopic procedures. Since many data that we receive from literature, is seen that laparoscopic method is very safe and effective in all ages. In an elegant study were considered 53 children who perform laparoscopic and open fundoplication. Characteristic of this study is that there are deals under 1 year old child. These are divided into two groups 39 are operated with laparoscopy and 14 are operated with open method. These two groups were compared with each other for operation time, meal time, complications and recurrences. It is seen that the time was $120+/-24 \mathrm{~min}$ 
operators to laparoscopic group and $91+/-21 \mathrm{~min}$ for food began $+/-0.31 .3+/-0.9$ days and 3 days respectively. Total food reached $1.7+/-0.6$ with laparoscopic group and 1.3 / 0.9 with laparatomy group. Recurrences are at rations $2 / 14$ and $1 / 39$ for the respective groups.

\section{Conclusions}

In conclusion, it is seen that sparing incision infant morbidity fundoplication by Nissen, performed with laparoscopy has the same success as was conducted at the open method. Regime and placement of food is in both cases in the same efficiency at both operatedgroups. Laparoscopic Nissen fundoplication is safe for treating esophagogastric reflux in children, provide similar results as open procedures with significant shorter hospital stay.

\section{References}

[1] The infant seat as treatment for gastroesophageal reflux. The New England Journal of Medicine. 1984 Feb 23; 310 (8): $527-$ 8. PubMed PMID: 6694700. Epub 1984/02/23.eng.

[2] Faure C. [Position and sudden death of the infant]. Pressemedicale. 1995 Dec 16-23; 24 (39): 1879-81. PubMed PMID: 8745534. Epub 1995/12/16. Position et mort subite du nourrisson. fre.

[3] Suffocation deaths associated with use of infant sleep positioners--United States, 1997-2011. MMWR Morbidity and mortality weekly report. 2012 Nov 23; 61 (46): 933-7. PubMed PMID: 23169313. Epub 2012/11/22.eng.
[4] Vandenplas Y, Benatar A, Cools F, Arana A, Hegar B, Hauser B. Efficacy and tolerability of cisapride in children. Paediatric drugs. 2001; 3 (8): 559-73. PubMed PMID: 11577921.

[5] Quigley EM. Cisapride: What can we learn from the rise and fall of a prokinetic? Journal of digestive diseases. 2011 Jun; 12 (3): 147-56. PubMed PMID:21615867. Epub 2011/05/28.eng.

[6] Tjon JA, Pe M, Soscia J, Mahant S. Efficacy and Safety of Proton Pump Inhibitors in the Management of Pediatric Gastroesophageal Reflux Disease. Pharmacotherapy. 2013 May 26. PubMed PMID: 23712734.

[7] Canani RB, Cirillo P, Roggero P, Romano C, Malamisura B, Terrin G, et al. Therapy with gastric acidity inhibitors increases the risk of acute gastroenteritis and communityacquired pneumonia in children. Pediatrics. 2006 May; 117 (5): e817-20. PubMed PMID: 16651285.

[8] Maureen Moore, Cheguevara Afaneh, Daniel Benhuri, Caroline Antonacci, Jonathan Abelson, and Rasa Zarnegar; "Gastroesophageal reflux disease: A review of surgical decision making"; World J Gastrointest Surg. 2016 Jan 27; 8 (1): 77-83. Published online 2016 Jan 27. doi:10.4240/wjgs.v8.i1.77PMCID: PMC4724590.

[9] Su F, Zhang C, Ke L, Wang Z, Li Y, Li H, Du Z.; "Efficacy comparison of laparoscopic Nissen, Toupet and Dor fundoplication in the treatment of hiatal hernia complicated with gastroesophageal reflux disease"; Zhonghua Wei Chang Wai Ke Za Zhi. 2016 Sep 25; 19 (9): 1014-1020.

[10] Mauritz FA, Rinsma NF, van Heurn EL, Sloots CE, Siersema PD, Houwen RH, van der Zee DC, Masclee AA, Conchillo JM, Van Herwaarden-Lindeboom MY; "Esophageal mucosal integrity improves after laparoscopic antireflux surgery in children with gastroesophageal reflux disease"; Surg Endosc. 2016 Nov 1. [Epub ahead of print]. 